\title{
Long-term efficacy of immune checkpoint inhibitors in advanced NSCLC: challenges and opportunities - a commentary of the 3-year follow-up of the KEYNOTE-001 trial
}

\author{
Alessandro Russo ${ }^{1,2}$, Katherine A. Scilla ${ }^{1}$, Christian Rolfo ${ }^{1}$ \\ ${ }^{1}$ University of Maryland Medical Center Greenebaum Comprehensive Cancer Center, Baltimore, MD, USA; ${ }^{2}$ Medical Oncology Unit A.O. Papardo \\ \& Department of Human Pathology, University of Messina, Messina, Italy \\ Correspondence to: Prof. Dr. Christian Rolfo, MD, PhD, MBA, Dr.h.c. Director of Thoracic Medical Oncology and Early Clinical Trials at University \\ of Maryland Medical Center, Greenebaum Comprehensive Cancer Center, 22 S Greene Street Rm. N9E08, Baltimore, MD 21201, USA. \\ Email: christian.rolfo@umm.edu. \\ Comment on: Leighl NB, Hellmann MD, Hui R, et al. Pembrolizumab in patients with advanced non-small-cell lung cancer (KEYNOTE-001): 3-year \\ results from an open-label, phase 1 study. Lancet Respir Med 2019;7:347-57
}

Submitted Jun 06, 2019. Accepted for publication Jun 12, 2019.

doi: $10.21037 /$ tcr.2019.06.24

View this article at: http://dx.doi.org/10.21037/tcr.2019.06.24

Treatment of advanced non-small cell lung cancer (NSCLC) has evolved considerably over the past two decades, with improved survival outcomes in a significant proportion of patients due to the development of new effective systemic therapies. The refinement of the therapeutic approach with a molecularly-based strategy has led to unprecedented results in selected patient populations harboring actionable oncogene drivers $(20-25 \%$ of all NSCLC patients). However, until recently, the survival of non-oncogene-addicted NSCLC patients was only modestly affected by novel anticancer therapies, with median survival ranging from $\sim 10-12$ months in squamous NSCLC $(1,2)$ and $\sim 13-15$ months in non-squamous NSCLC $(3,4)$ in the pre-immunotherapy era. Over the last few years, the development of immunotherapy has revolutionized lung cancer treatment (5), with four different immune checkpoint inhibitors (ICIs) targeting the PD-1/ PD-L1 axis now approved by the U.S. Food and Drug Administration (FDA) and the European Medicines Agency (EMA) for multiple clinical indications. Several biomarkers have been studied to help determine which patients will derive the most therapeutic benefit from anti-PD-1/antiPD-L1 immunotherapy. However, predictive biomarkers for optimal patient selection are lacking, with PD-L1 expression being the main clinically applicable test at this time. A pooled analysis of the randomized phase III trials evaluating ICIs in pre-treated NSCLC showed that patients with PD-L1 positive tumors (PD-L1 tumor staining of $\geq 1 \%$ ) have significantly higher overall response rate (ORR) compared to PD-L1 negative tumors, suggesting that PD$\mathrm{L} 1$ overexpression is a predictive biomarker (6). However, PD-L1 immunohistochemical expression is an imperfect biomarker. Among those with positive PD-L1 expression, a significant proportion of NSCLC patients do not benefit from ICIs, even when using more stringent cut-off values (ORR 45\% in patients with PD-L1 expression $\geq 50 \%$ ) (7-9). Conversely, NSCLC patients with negative PD-L1 expression may also experience significant benefit from these agents (10-12).

Several questions regarding ICIs remain unanswered, including optimal treatment duration, identification of reliable predictive biomarkers, and long-term safety data among others.

In the Lancet Respiratory Medicine, Leighl et al. reported the 3-year follow-up of the phase I multicohort study KEYNOTE-001 (13), which evaluated safety and efficacy of pembrolizumab at different doses and schedules in advanced NSCLC in both pre-treated $(\mathrm{n}=449)$ and treatment-naïve $(\mathrm{n}=101)$ patients, as well as sought to define and validate PDL1 expression as predictive biomarker. In the original report, after a median follow-up of 10.9 months (range, 5.2-27.5), pembrolizumab was associated with relative favorable safety profile [treatment-related adverse events (AEs) of grade 3 or more reported in $9.5 \%$ of the patients], an ORR of $19.4 \%$, a 
median progression free survival (PFS) of 3.7 months, and a median overall survival (OS) of 12.0 months in the overall population. A tumor proportion score (TPS) of PD-L1 $\geq 50 \%$ was associated with a higher ORR and longer PFS and OS than a TPS $<50 \%$ in both previously untreated patients and previously treated patients (8). In the updated analysis (median follow-up of 34.5 months, IQR 32.2-37.4), Leighl et al. further provide evidence of efficacy of this agent in NSCLC in both pretreated and treatment-naïve patients with an ORR of $23 \%$ and $41 \%$ and median OS of 10.5 months (95\% CI, 8.6-13.2) and 22.3 months (95\% CI, 17.1-31.5), respectively. The proportion of patients alive at 24 months and 36 months were $49.0 \%$ and $26.4 \%$ for treatment-naïve patients and $29.9 \%$ and $19.0 \%$ for previously treated patients (13). Data on pretreated patients are in line with previous reports (14-16), suggesting that approximately $15-20 \%$ of patients might derive long-term benefit with ICIs. As expected, PD-L1 TPS $\geq 50 \%$ was predictive of higher long-term benefit in both treatmentnaïve (66.7\% vs. $37.3 \%$ 24-month rate and $25.2 \%$ vs. NR 36-month rate for TPS $\geq 50 \%$ and $1-49 \%$, respectively) and pretreated patients $(38.6 \%$ vs. $26.2 \%$ vs. $23.8 \%$ 24-month rate and $29.7 \%$ vs. $13.5 \%$ vs. $8.5 \%$ 36-month rate for TPS $\geq 50 \%, 1-49 \%$ and $<1 \%$, respectively) (13).

The results of this updated analysis are noteworthy for several reasons. First, the authors demonstrated no evidence of cumulative immune-related toxicity or late-onset grade 3-5 toxicity with longer exposure to pembrolizumab. This is similar to that reported in other studies with the same compound in NSCLC $(7,15)$ or with other anti-PD-1/PDL1 agents in NSCLC (16-18), with most grade $\geq 3$ treatmentrelated AEs observed within the first year of treatment (13). In addition, the clinicopathological characteristics of longterm survivors described in this report may help to identify patients deriving more benefit from ICIs.

The majority of patients who completed 2 years or more of pembrolizumab at data cutoff (48 patients) had a partial response (PR) or complete response (CR) as the best overall response $(80 \%$ and $89 \%$ in treatment-naïve and pre-treated patients, respectively) (13). In addition, these results are in line with previous reports $(95 \%$ of the patients who completed the planned 2 years of treatment in the KEYNOTE-010 and $75 \%$ of the 5 -year survivors in the CA-209-003 had a PR or CR) $(15,17)$ suggesting that patients experiencing durable response during ICIs derive the greatest benefit.

A possible differential effect of histology on long-term efficacy of ICIs has been suggested in this study, with a higher proportion of squamous NSCLC among previously treated patients who were 3 -year survivors (13). These data are in contrast with the results of the POPLAR study reporting a higher benefit among non-squamous NSCLCs (14) and with those of CA-209-003, CheckMate-017 and CheckMate-057 that did not find any significant correlation between histology and long-term benefit (15-17). Further studies must be conducted in order to clarify this specific issue.

An important emerging clinical question is whether there is optimal treatment duration of immune checkpoint blockade, as well as if ICIs can be resumed on disease progression after discontinuation. Of note, KEYNOTE-001 after an amendment allowed the discontinuation of treatment after 24 months in patients with response or stable disease or after 6 months in patients with CR and allowed for re-initiation of pembrolizumab upon disease progression. However, among 48 patients who completed 2 years of pembrolizumab treatment, $73 \%$ chose to continue study treatment and no information regarding subsequent progression or pembrolizumab re-initiation was provided (13). Some clinical data on this important issue are emerging from the KEYNOTE-010. Among 79 patients who completed the planned 35 courses of pembrolizumab, most had an ongoing response after a median follow-up of 43.4 months (35.7-49.8), with only 25 patients $(32 \%)$ experiencing progressive disease (PD). Of these progressing patients, 14 were re-challenged with the same agent, reporting an ORR of $43 \%$ and a disease control rate (DCR) of $79 \%$ (15). These data suggest that most of the patients discontinuing treatment after 2 years of pembrolizumab continue to derive benefit without the need of further treatment and that rechallenge with ICIs is feasible after PD after an immunotherapy-free interval. Similar results have been demonstrated in the phase 1 CA 209-003 study with nivolumab (17), albeit the limited number of patients included in this analysis does not allow drawing definitive conclusions. However, the definition of optimal immunotherapy treatment duration is far from clear. In the CheckMate-153 trial, randomization of advanced NSCLC patients after 1 year of nivolumab to continuous treatment versus discontinuation was superior in terms of PFS (HR 0.42) independently of tumor response (CR/PR vs. SD), with a favorable trend in OS (HR 0.63). After a median follow-up time post-randomization of 14.9 months, $49 \%$ of the patients in the experimental arm progressed and $79 \%$ were retreated with nivolumab, with a median duration of treatment of 3.8 months (19). In 
addition, a recent retrospective study of 185 patients with advanced melanoma who electively discontinued anti-PD-1 therapy in the absence of disease progression or treatmentlimiting toxicity, after a median time on treatment of 12 months (range, 0.7-43) and a median follow-up of 18 months showed that $78 \%$ of patients remained progression free. However, the response to treatment in this study was significantly associated with outcome, since subsequent PD was less frequent in patients with CR (14\%) compared to patients with PR (32\%) and SD (50\%). In addition, 6 out of $19(32 \%)$ patients who were retreated with an anti-PD-1 antibody at the time of PD achieved a new anti-tumor response (20). Furthermore, a retrospective study evaluated the outcome of 13 patients with different solid tumors who discontinued ICIs in phase I trials as per protocol without PD. The median time free-treatment after ICI discontinuation was 12.6 months (range, 4-39.7), with 8 patients re-treated upon disease progression. Rechallenge with an ICI was associated with inferior ORR $(25 \% \mathrm{vs}$. $85 \%$ ), and shorter PFS (12.9 vs. 24.4 months) compared to initial treatment course (21).

Data emerging from these studies suggest that selected patients might electively discontinue treatment with ICIs, although the optimal treatment duration and the characteristics of patients benefiting from this strategy are relatively unknown and should be prospectively evaluated in a randomized clinical trial. Until then, treatment with ICIs in NSCLC could be continued according to the approval label of each drug, taking in consideration the possible increase of drug and cost toxicities.

Another important issue analyzed in the paper of Leigh et al. is the impact of radiotherapy on outcome of patients treated with ICIs. An initial report of NSCLC patients treated in the KEYNOTE 001 trial at a single institution (University of California, Los Angeles, CA, USA) suggested that previous treatment with radiotherapy resulted in longer PFS and OS with pembrolizumab compared with patients who did not have previous radiotherapy, with an acceptable safety profile (22). These results suggested a possible positive interaction between the two treatment modalities, resulting in an improved immunotherapy outcome. However, these findings were not confirmed in the overall study population, with no significant differences between patients who had received prior radiotherapy or not in terms of median OS (9.1 vs. 13.2 months) and 36-month OS rate (18.4\% vs. 19.5\%) (13).

In summary, emerging long-term follow-up of clinical trials with ICIs in NSCLC can provide useful information in clinical practice (Table 1) and the updated results of KEYNOTE-001 add further evidence regarding longterm safety and efficacy of single agent pembrolizumab in advanced NSCLC. However, several questions remain unanswered including optimal treatment duration, ICI rechallenge after elective treatment discontinuation, and identification of reliable predictive biomarkers of long-term response. These unmet medical needs should be addressed in prospective randomized clinical trials.

Table 1 Long-term results with immune checkpoint inhibitors in advanced NSCLC

\begin{tabular}{|c|c|c|c|c|c|c|c|c|c|c|}
\hline Trial & Phase & $\mathrm{ICl} \operatorname{arm}(\mathrm{s})$ & $\begin{array}{l}\text { Treatment } \\
\text { duration }\end{array}$ & $\begin{array}{l}\text { Population } \\
{[\mathrm{n}]}\end{array}$ & $\begin{array}{l}\text { PD-L1 } \\
\text { selection }\end{array}$ & $\begin{array}{l}\text { Median } \\
\text { FU }\end{array}$ & $\begin{array}{l}\text { Median OS } \\
(95 \% \mathrm{Cl})\end{array}$ & $\begin{array}{l}2-y r \\
\text { OS }\end{array}$ & $\begin{array}{l}3-y r \\
\text { OS }\end{array}$ & $\begin{array}{l}5-y r \\
\text { OS }\end{array}$ \\
\hline \multirow[t]{2}{*}{ KEYNOTE-001 (13) } & 1 & Pembrolizumab & Until PD* & $\begin{array}{l}1^{\text {st }} \text { line NSCLC } \\
{[101]^{\ddagger}}\end{array}$ & $\geq 1 \%$ & $34.5 \mathrm{mos}$ & $\begin{array}{l}22.3(17.1- \\
31.5) \mathrm{mos}\end{array}$ & $49 \%$ & $26.4 \%$ & - \\
\hline & & Pembrolizumab & & $\begin{array}{l}\text { Pretreated } \\
\text { NSCLC [449] }\end{array}$ & $\begin{array}{l}\text { All } \\
\text { comers }\end{array}$ & & $\begin{array}{l}10.5 \text { (8.6- } \\
13.2) \text { mos }\end{array}$ & $29.9 \%$ & $19 \%$ & \\
\hline KEYNOTE-010 (15) & $2 / 3$ & Pembrolizumab & $\begin{array}{l}24 \text { months } \\
\text { or until PD }\end{array}$ & $\begin{array}{l}\text { Pretreated } \\
\text { NSCLC [690] }\end{array}$ & $\geq 1 \%$ & $42.6 \mathrm{mos}$ & $\begin{array}{l}11.8(10.4- \\
13.1) \mathrm{mos}\end{array}$ & - & $\begin{array}{c}23 \% / \\
11 \%\end{array}$ & - \\
\hline KEYNOTE-024 (7) & 3 & Pembrolizumab & 24 months & $\begin{array}{l}1^{\text {st }} \text { line, EGFR/ALK } \\
\text { WT NSCLC [154] }\end{array}$ & $\geq 50 \%$ & $25.2 \mathrm{mos}$ & $\begin{array}{l}30(18.3-\mathrm{NR}) \\
\text { mos }\end{array}$ & $70.3 \%$ & $51.5 \%$ & - \\
\hline CHECKMATE-017 (16) & 3 & Nivolumab & Until PD & $\begin{array}{l}\text { Pretreated } \\
\text { squamous } \\
\text { NSCLC [131] }\end{array}$ & $\begin{array}{l}\text { All } \\
\text { comers }\end{array}$ & $\begin{array}{l}3-y r \\
\text { minimum }\end{array}$ & $\begin{array}{l}9.23 \text { (7.33- } \\
12.62) \text { mos }\end{array}$ & $23 \%$ & $16 \%$ & - \\
\hline CHECKMATE-057 (16) & 3 & Nivolumab & Until PD & $\begin{array}{l}\text { Pretreated non- } \\
\text { squamous } \\
\text { NSCLC [287] }\end{array}$ & $\begin{array}{l}\text { All } \\
\text { comers }\end{array}$ & $\begin{array}{l}3-y r \\
\text { minimum }\end{array}$ & $\begin{array}{l}12.21 \text { (9.66- } \\
15.08) \text { mos }\end{array}$ & $29 \%$ & $18 \%$ & - \\
\hline
\end{tabular}

Table 1 (continued) 
Table 1 (continued)

\begin{tabular}{|c|c|c|c|c|c|c|c|c|c|c|}
\hline Trial & Phase & $\mathrm{ICl} \operatorname{arm}(\mathrm{s})$ & $\begin{array}{l}\text { Treatment } \\
\text { duration }\end{array}$ & $\begin{array}{l}\text { Population } \\
\text { [n] }\end{array}$ & $\begin{array}{l}\text { PD-L1 } \\
\text { selection }\end{array}$ & $\begin{array}{l}\text { Median } \\
\text { FU }\end{array}$ & $\begin{array}{l}\text { Median OS } \\
(95 \% \mathrm{Cl})\end{array}$ & $\begin{array}{l}2-y r \\
\text { OS }\end{array}$ & $\begin{array}{l}3-y r \\
\text { OS }\end{array}$ & $\begin{array}{l}5-y r \\
\text { OS }\end{array}$ \\
\hline CA209-003 (17) & 1 & Nivolumab & 96 weeks & $\begin{array}{l}\text { Pretreated } \\
\text { NSCLC [129] }\end{array}$ & $\begin{array}{l}\text { All } \\
\text { comers }\end{array}$ & $\begin{array}{l}58.28 \text { mos } \\
\text { minimum }\end{array}$ & $\begin{array}{l}9.9(7.8- \\
12.4) \mathrm{mos}\end{array}$ & $25 \%$ & $18 \%$ & $16 \%$ \\
\hline POPLAR $(14,23)$ & 2 & Atezolizumab & Until PD & $\begin{array}{l}\text { Pretreated } \\
\text { NSCLC [144] }\end{array}$ & $\begin{array}{l}\text { All } \\
\text { comers }\end{array}$ & $38 \mathrm{mos}$ & $\begin{array}{l}12.6(9 \cdot 7- \\
16.4) \mathrm{mos}\end{array}$ & $32.2 \%$ & $18.7 \%$ & - \\
\hline OAK (18) & 3 & Atezolizumab & Until PD & $\begin{array}{l}\text { Pretreated } \\
\text { NSCLC [425] }\end{array}$ & $\begin{array}{l}\text { All } \\
\text { comers }\end{array}$ & $28 \mathrm{mos}$ & $\begin{array}{l}13.8(11.8- \\
15.7) \mathrm{mos}\end{array}$ & $30.9 \%$ & - & - \\
\hline \multirow[t]{2}{*}{ MYSTIC (24) } & 3 & Durvalumab & Until & $\begin{array}{l}1^{\text {st }} \text { line, EGFR/ALK } \\
\text { WT NSCLC [374] }\end{array}$ & $\begin{array}{l}\text { All } \\
\text { comers }\end{array}$ & $30.2 \operatorname{mos}^{\dagger}$ & $\begin{array}{l}16.3(12.2- \\
20.8)^{\dagger} \mathrm{mos}\end{array}$ & $38.3 \%^{\dagger}$ & - & - \\
\hline & & $\begin{array}{l}\text { Durvalumab- } \\
\text { Tremelimumab }\end{array}$ & $P D^{\star \star}$ & \multicolumn{2}{|l|}{$\begin{array}{l}1^{\text {st }} \text { line, EGFR/ALK } \\
\text { WT NSCLC [372] }\end{array}$} & & $\begin{array}{l}11.9(9.0- \\
17.7)^{\dagger} \mathrm{mos}\end{array}$ & $35.4 \%^{\dagger}$ & & \\
\hline
\end{tabular}

NSCLC, non-small cell lung cancer; PD, progressive disease; WT, wild type; mos, months; yr, year; Cl, confidence interval; NR, not reached; FU, follow-up. *, after a protocol amendment in April 2016, discontinuation after 24 months of treatment and resume upon disease progression was allowed; **, in the durvalumab-tremelimumab arm, durvalumab was continued until PD after 4 courses of anti-PD1 + CTLA-4 courses; ${ }^{\ddagger}$, after a protocol amendment, the enrollment in this arm was limited to EGFR/ALK WT patients; ${ }^{\dagger}$, PD-L1 $\geq 25 \%$ subgroups.

\section{Acknowledgments}

Funding: None.

\section{Footnote}

Provenance and Peer Review: This article is commissioned and reviewed by the Section Editor Wei Xu (Division of Respiratory Disease, Department of Geriatrics, the First Affiliated Hospital of Nanjing Medical University, Nanjing, China).

Conflicts of Interest: Dr. Rolfo reports personal fees from Novartis, personal fees from MSD, non-financial support from OncoDNA, personal fees and non-financial support from GuardantHealth, outside the submitted work. All other authors have no conflicts of interest to declare.

Ethical Statement: The authors are accountable for all aspects of the work in ensuring that questions related to the accuracy or integrity of any part of the work are appropriately investigated and resolved.

Open Access Statement: This is an Open Access article distributed in accordance with the Creative Commons Attribution-NonCommercial-NoDerivs 4.0 International License (CC BY-NC-ND 4.0), which permits the noncommercial replication and distribution of the article with the strict proviso that no changes or edits are made and the original work is properly cited (including links to both the formal publication through the relevant DOI and the license). See: https://creativecommons.org/licenses/by-nc-nd/4.0/.

\section{References}

1. Thatcher N, Hirsch FR, Luft AV, et al. Necitumumab plus gemcitabine and cisplatin versus gemcitabine and cisplatin alone as first-line therapy in patients with stage IV squamous non-small-cell lung cancer (SQUIRE): an open-label, randomised, controlled phase 3 trial. Lancet Oncol 2015;16:763-74.

2. Socinski MA, Bondarenko I, Karaseva NA, et al. Weekly nab-paclitaxel in combination with carboplatin versus solvent-based paclitaxel plus carboplatin as first-line therapy in patients with advanced non-small-cell lung cancer: final results of a phase III trial. J Clin Oncol 2012;30:2055-62.

3. Paz-Ares LG, de Marinis F, Dediu M, et al.

PARAMOUNT: Final overall survival results of the phase III study of maintenance pemetrexed versus placebo immediately after induction treatment with pemetrexed plus cisplatin for advanced nonsquamous non-small-cell lung cancer. J Clin Oncol 2013;31:2895-902.

4. Ciuleanu T, Brodowicz T, Zielinski C, et al. Maintenance pemetrexed plus best supportive care versus placebo plus best supportive care for non-small-cell lung cancer: a randomised, double-blind, phase 3 study. Lancet 2009;374:1432-40.

5. Corrales L, Scilla K, Caglevic C, et al. Immunotherapy in 
Lung Cancer: A New Age in Cancer Treatment. Adv Exp Med Biol 2018;995:65-95.

6. Passiglia F, Bronte G, Bazan V, et al. PD-L1 expression as predictive biomarker in patients with NSCLC: a pooled analysis. Oncotarget 2016;7:19738-47.

7. Reck M, Rodríguez-Abreu D, Robinson AG, et al. Updated Analysis of KEYNOTE-024: Pembrolizumab Versus Platinum-Based Chemotherapy for Advanced NonSmall-Cell Lung Cancer With PD-L1 Tumor Proportion Score of 50\% or Greater. J Clin Oncol 2019;37:537-46.

8. Garon EB, Rizvi NA, Hui R, et al. Pembrolizumab for the treatment of non-small-cell lung cancer. N Engl J Med 2015;372:2018-28.

9. Mok TSK, Wu YL, Kudaba I, et al. Pembrolizumab versus chemotherapy for previously untreated, PD-L1expressing, locally advanced or metastatic non-small-cell lung cancer (KEYNOTE-042): a randomised, open-label, controlled, phase 3 trial. Lancet 2019;393:1819-30.

10. Borghaei H, Paz-Ares L, Horn L, et al. Nivolumab versus Docetaxel in Advanced Nonsquamous Non-Small-Cell Lung Cancer. N Engl J Med 2015;373:1627-39.

11. Brahmer J, Reckamp KL, Baas P, et al. Nivolumab versus Docetaxel in Advanced Squamous-Cell Non-Small-Cell Lung Cancer. N Engl J Med 2015;373:123-35.

12. Rittmeyer A, Barlesi F, Waterkamp D, et al. Atezolizumab versus docetaxel in patients with previously treated non-small-cell lung cancer (OAK): a phase 3, openlabel, multicentre randomised controlled trial. Lancet 2017;389:255-65.

13. Leighl NB, Hellmann MD, Hui R, et al. Pembrolizumab in patients with advanced non-small-cell lung cancer (KEYNOTE-001): 3-year results from an open-label, phase 1 study. Lancet Respir Med 2019;7:347-57.

14. Mazières J, Park K, Lewanski C, et al. 136PD_PR 3-year survival and duration of response in randomized phase II study of atezolizumab (atezo) vs docetaxel (doc) in 2L NSCLC (POPLAR). J Thorac Oncol 2018;13:S79.

15. Herbst RS, Garon EB, Kim D-W, et al. LBA4Long-term follow-up in the KEYNOTE-010 study of pembrolizumab (pembro) for advanced NSCLC, including in patients (pts) who completed 2 years of pembro and pts who received a second course of pembro. Ann Oncol 2018;29. doi: 10.1093/annonc/mdy511.003.

16. Vokes EE, Ready N, Felip E, et al. Nivolumab versus docetaxel in previously treated advanced non-small-cell lung cancer (CheckMate 017 and CheckMate 057): 3-year update and outcomes in patients with liver metastases. Ann Oncol 2018;29:959-65.
17. Gettinger S, Horn L, Jackman D, et al. Five-Year FollowUp of Nivolumab in Previously Treated Advanced NonSmall-Cell Lung Cancer: Results From the CA209-003 Study. J Clin Oncol 2018;36:1675-84.

18. Fehrenbacher L, von Pawel J, Park K, et al. Updated Efficacy Analysis Including Secondary Population Results for OAK: A Randomized Phase III Study of Atezolizumab versus Docetaxel in Patients with Previously Treated Advanced Non-Small Cell Lung Cancer. J Thorac Oncol 2018;13:1156-70.

19. Spigel D, Mcleod M, Hussein M, et al. 1297 O Randomized results of fixed-duration (1-yr) vs continuous nivolumab in patients (pts) with advanced non-small cell lung cancer (NSCLC). Ann Oncol 2017;28. doi: 10.1093/ annonc/mdx380.002.

20. Jansen YJL, Rozeman EA, Mason R, et al. Discontinuation of anti-PD-1 antibody therapy in the absence of disease progression or treatment limiting toxicity: clinical outcomes in advanced melanoma. Ann Oncol 2019;30:1154-61.

21. Bernard-Tessier A, Baldini C, Martin P, et al. Outcomes of long-term responders to anti-programmed death 1 and anti-programmed death ligand 1 when being rechallenged with the same anti-programmed death 1 and antiprogrammed death ligand 1 at progression. Eur J Cancer 2018;101:160-4.

22. Shaverdian N, Lisberg AE, Bornazyan K, et al. Previous radiotherapy and the clinical activity and toxicity of pembrolizumab in the treatment of non-small-cell lung cancer: a secondary analysis of the KEYNOTE-001 phase 1 trial. Lancet Oncol 2017;18:895-903.

23. Fehrenbacher L, Spira A, Ballinger M, et al. Atezolizumab versus docetaxel for patients with previously treated non-small-cell lung cancer (POPLAR): a multicentre, open-label, phase 2 randomised controlled trial. Lancet 2016;387:1837-46.

24. Rizvi NA, Chul Cho B, Reinmuth N, et al. LBA6 Durvalumab with or without tremelimumab vs platinumbased chemotherapy as first-line treatment for metastatic non-small cell lung cancer: MYSTIC. Ann Oncol 2018;29. doi: 10.1093/annonc/mdy511.

Cite this article as: Russo A, Scilla KA, Rolfo C. Long-term efficacy of immune checkpoint inhibitors in advanced NSCLC: challenges and opportunities - a commentary of the 3-year follow-up of the KEYNOTE-001 trial. Transl Cancer Res 2019;8(Suppl 6):S598-S602. doi: 10.21037/tcr.2019.06.24 